\title{
Confocal Laser Scanning Microscope, Raman Microscopy and Western Blotting to Evaluate Inflammatory Response after Myocardial Infarction
}

\author{
Irene Riezzo*, Santina Cantatore, Dania De Carlo, Carmela Fiore, Margherita Neri, Emanuela Turillazzi and \\ Vittorio Fineschi
}

Department of Forensic Pathology, University of Foggia, Italy

\begin{abstract}
Cardiac muscle necrosis is associated with inflammatory cascade that clears the infarct from dead cells and matrix debris, and then replaces the damaged tissue with scar, through three overlapping phases: the inflammatory phase, the proliferative phase and the maturation phase.

Western blotting, laser confocal microscopy, Raman microscopy are valuable tools for studying the inflammatory response following myocardial infarction both humoral and cellular phase, allowing the identification and semiquantitative analysis of proteins produced during the inflammatory cascade activation and the topographical distribution and expression of proteins and cells involved in myocardial inflammation. Confocal laser scanning microscopy (CLSM) is a relatively new technique for microscopic imaging, that allows greater resolution, optical sectioning of the sample and three-dimensional reconstruction of the same sample. Western blotting used to detect the presence of a specific protein with antibody-antigen interaction in the midst of a complex protein mixture extracted from cells, produced semi-quantitative data quite easy to interpret. Confocal Raman microscopy combines the three-dimensional optical resolution of confocal microscopy and the sensitivity to molecular vibrations, which characterizes Raman spectroscopy.

The combined use of western blotting and confocal microscope allows detecting the presence of proteins in the sample and trying to observe the exact location within the tissue, or the topographical distribution of the same. Once demonstrated the presence of proteins (cytokines, chemokines, etc.) is important to know the topographical distribution, obtaining in this way additional information regarding the extension of the inflammatory process in function of the time stayed from the time of myocardial infarction. These methods may be useful to study and define the expression of a wide range of inflammatory mediators at several different timepoints providing a more detailed analysis of the time course of the infarct.
\end{abstract}

Keywords: Confocal laser microscope, cytokines, myocardial infarction, Raman microscope, western blotting.

\section{INTRODUCTION}

Once myocardial infarction occurs, infracted myocardium undergoes a progressive sequence of changes consisting of loss of contraction of a myocardial region (atonic death), myocellular stretching, shown by prominent I bands demonstrated electron microscopically [1] and by histology [2], that represents the first functional change following a myocardial infarct followed by inflammation and replacement with scar tissue [3, 4].

The earliest histological signs are visible within $30 \mathrm{~min}$ of infarct onset and consist of mild myofiber eosinophilia and elongation of sarcomeres and nuclei. The latter show peripheral chromatin clumping followed by a progressive fading with their disappearance within 10 to 15 days. Other typical changes occur after 6 to $8 \mathrm{~h}$ with a margination of polymorphonuclear (PMN) leukocytes in vessels at the periphery of the necrotic zone followed by an infiltration of these elements, without fibrin or hemorrhage, into the dead

*Address correspondence to this Author at the Department of Forensic Pathology, Ospedale Colonnello D'Avanzo, Viale degli Aviatori 1, 71100 Foggia, Italy; Tel: +39 0881 736902; Fax: +39 0881 736903;

E-mail: ireneriezzo@tin.it tissue. A crowd of PMN is visible along a line between infiltrated and non-infiltrated necrotic myocardium in large areas of necrosis. PMNs disappear by lysis within 5 to 7 days, according to the size of the necrosis, without evidence of related myocellular change. Again at the periphery of the necrotic myocardium, a repair process starts at 1 week by macrophagic digestion of tissue within the sarcolemmal sheets and progressive collagenization to form a dense scar.

In general, no pathognomonic histologic sign is visible within 6 to $8 \mathrm{~h}$ of survival after onset when PMN infiltration starts [4].

However a large number of studies, both human and animal, have demonstrated that cardiac muscle necrosis is associated with inflammatory cascade that clears the infarct from dead cells and matrix debris, and then replaces the damaged tissue with scar [5].

Indeed the infarct healing can be divided into three overlapping phases: the inflammatory phase, the proliferative phase and the maturation phase $[5,6]$.

Western blotting, laser confocal microscopy, Raman microscopy are valuable tools for studying the inflammatory response following myocardial infarction, allowing the iden- 
tification and semiquantitative analysis of proteins produced during the inflammatory cascade activation and the topographical distribution and expression of proteins and cells involved in myocardial inflammation.

Several experimental studies have been conducted to quantify the expression of proteins (cytokines, chemokines, etc.) and to observe their expression in the tissues, as well as the cells involved, contributing to the definition of the inflammatory response to myocardial infarction [7].

\section{CONFOCAL LASER SCANNING MICROSCOPY}

Confocal laser scanning microscopy (CLSM) is a relatively new technique for microscopic imaging. It has found wide applications in the biological sciences [8,9] and can also be used in specific fields of forensic investigation, with specific regard to ballistics, forensic histopathology and toxicological pathology [10].

Thanks to its non-invasive nature of optical sectioning, both on living and fixed cells, enables to obtain images with an optimal spatial resolution but without any dramatic alteration of their "architecture". CLSM provides precious information regarding the distribution of a substance in the entire volume of the sample (e.g. fragment of tissue or cultured cells) and of structural and nonstructural components that can emit a luminous signal, either by themselves or by means of specific stain, which will emit light when they are hit by a laser beam. CLSM also provides information regarding the various focal planes of the sample (information about depth).

The primary value of CLSM to the forensic scientist is its ability to produce optical sections through a $3 \mathrm{D}$ specimen, e.g. an entire cell or a piece of tissue that, to a good approximation, contains information from only one focal plane. By moving the focal plane of the instrument step by step through the depth of the specimen, a series of optical sections can be recorded [11]. This property of the CLSM is fundamental for solving 3D biological problems where information from regions distant from the plane of focus can obscure the image (thick objects).

Moreover objects may be viewed in a four-dimensional space (4D microscopy, xyzt) via a spatial analysis, repeated in time, and then combined with the spectral characterization of luminous signals coming from samples under examination (five-dimensional, 5D microscopy: xyzt $\lambda$ ).

It allows greater resolution, optical sectioning of the sample and three-dimensional reconstruction of the same sample [12-16].

\section{WESTERN BLOTTING}

Western blotting or immunoblotting because an antibody is used to specifically detect its antigen was introduced by Towbin, et al. in 1979 [17]. It is used to detect the presence of a specific protein with antibody-antigen interaction in the midst of a complex protein mixture extracted from cells.

The western blotting procedure is fairly simple and usually consists of four separate steps: 1) electrophoretic separation of protein or of nucleic acid fragments in the sample; 2) transfer to and immobilization on paper support; 3) binding of analytical probe to the target molecule on paper; 4) and visualization of bound probe. Once detected, the target protein will be visualized as a band on a blotting membrane, Xray film, or an imaging system. The specific antibodies to the protein under examination are needed for western blotting. The sources of these antibodies may be serum samples (for example, from patients with known infections), purified polyclonal antibody preparations, or monoclonal antibodies. In this way the procedure essentially confirms the identity of a target protein. As a consequence of the interaction of antibody and antigen the target protein (the antigen) when immobilized on a paper support can be identified with antibodies. The mixture containing the protein under investigation is first resolved into its components by electrophoresis in polyacrylamide gels, and the proteins are then transferred to nitrocellulose paper. The primary antibody binds to its target protein and is immobilized on the blotting support. The antigen-antibody complex can then be identified with antibodies to the primary antibodies, which are labeled with radioactive iodine, and can then be visualized by autoradiography. The labeling antibody can be removed and the protein studied further [18].

The data produced with a western blot is usually quite easy to interpret. In the majority of cases, bands corresponding to the target protein will become visible upon treatment of the blot with substrate. Their identity is confirmed by comparison to molecular weight markers (for size) and a positive control (size and signal). In some cases the data may be more complex, showing unexpected sizes, multiple bands, or alteration in bands following a particular treatment. When data does not match expectations, there may be clues as to what should be investigated to determine the reason. Conversely, when bands are seen at higher levels than expected, this may indicate an actual increase in mass due to glycosylation or multimer formation.

The data obtained with western blot are typically regarded as semi-quantitative. It indeed provides a relative comparison of the levels of proteins, but not an absolute measure of the quantity of a specific target protein in a biological sample. The reason for this is two-fold: first, there will be variations in loading and transfer rates between the samples in separate lanes and on separate blots that will need to be normalized before a more precise comparison can be made; second, the signal generated will not be linear across the concentration range of samples due to substrate availability and linear responsiveness of the detection method. Since the signal produced is not linear, it should not be used to attach a precise concentration to a particular sample [17, 1924]. In any case it represents now a routine technique for protein analysis.

\section{RAMAN MICROSCOPY}

The Raman spectroscopy is a technique, which enables us to discover information on the molecular composition of materials, and then to identify their nature. This technique is based on the diffusion of a monochromatic radiation incident on the surface of an object, which can be absorbed, reflected or diffused, and it is an ideal tool for identifying and distinguishing between organic and inorganic molecules and crystals. Specifically the theory behind the Raman spectroscopy is based on the inelastic scattering of low-intensity, nonde- 
structive laser light by solid, liquid or gas sample. It was realized that Raman spectroscopy was a convenient probe of the vibrational energy levels within a molecule, which easily provides molecular fingerprints. Another unique advantage of Raman spectroscopy is it can be used to selectively excite a needed portion of the molecule by changing the excitation wavelength. On top of that Raman spectroscopy doesn't required any sample preparation, samples are not destroyed, water bands are usually small and easily subtracted and Raman spectra usually contain sharp bands that are characteristic of the specific molecular bonds in the sample. The intensity of the bands in a Raman spectrum is proportional to the concentration of the corresponding molecules and thus can be used for quantitative analysis. In biological samples, such as cells and tissues, infrared spectra often show broad spectral features which can give information regarding cellular components. However, Raman spectra give this information as well as more detailed information regarding the constituents of these specific components allowing good specificity for qualitative analysis and for discrimination among similar materials.

The spectral information in confocal microscopy can be obtained through different techniques such as Absorption, Reflection, Transmission, Emission, Photoluminescence, Fluorescence or Raman spectroscopy.

Confocal Raman spectrometers are today relatively commonplace in many laboratories undertaking forensicrelated studies [25]. Confocal optics enables both better lateral spatial and depth resolution measurements. The sample is mounted on an $x-y-=$ translation stage, where $x-y$ represents the normal (horizontal) focal plane and $\mathrm{z}$ the depth (vertical, axial) direction; the sample can be either viewed visually, photographed or videoed, or interrogated using Raman spectroscopy. The latter depending on the instrumentation may be accomplished either as a single or series (linear or two-dimensional map) of single point measurements, and/or a depth profile, or as a series of images at specific wave numbers. For convenience, many micro-samples may simply be placed onto a conventional microscope slide supported on the standard microscope sampling stage. Raman spectroscopic imaging sometimes referred to as Raman chemical imaging $(\mathrm{CI})$, is used to provide a visual perception of specimens that may be spatially heterogeneous in composition and structure [26]. The term "chemical imaging" is often applied to describe molecular or molecular group specific images generated from measurements by various vibrational spectroscopy techniques [27].

Confocal Raman microscopy combines the threedimensional optical resolution of confocal microscopy and the sensitivity to molecular vibrations, which characterizes Raman spectroscopy. In confocal Raman microscopy, recording the integrated intensity of characteristic Raman lines of the substances involved can image the chemical composition of a sample.

\section{THE INFLAMMATORY RESPONSE AFTER MYO- CARDIAL INFARCTION}

The inflammatory response involves a humoral phase and a cellular phase. Cells dying by necrosis release their intracellular contents ("danger signals") and initiate an intense inflammatory response by activating innate immune mechanisms [28]. Cardiomyocyte death triggers rapid activation of the complement cascade, generates free radicals and activates Toll-Like Receptor (TLR)-mediated pathways [29], which play a significant role in triggering the post-infarction inflammatory response by activating the nuclear factor (NF)$\kappa \mathrm{B}$ system [6]. The activation of NF- $\kappa \mathrm{B}$ in resident myocardial cells induces expression of cytokines (TNF-alpha, IL-6, IL-1), chemokines and adhesion molecules [6, 28, 30]. The result is recruitment of neutrophil and monocyte into the infarcted area [31, 32]. Chemokines are secreted into the subendothelium and are also displayed in the luminal surface of endothelial cells, where they bind to chemokine receptors expressed by circulating leukocytes [33]. This interaction results in integrin-mediated adhesion, followed by diapedesis of leukocytes into the subendothelial space [28]. Cells recruitment is regulated by complement activation, release and induction of MCP-1 (monocyte chemoattractant protein-1) and IL-8. Resident mast cells release preformed histamine and TNF-alpha and initiated cytokine cascade, which leads to IL-6 synthesis in mononuclear cells and myocytes. The myocytes in the ischemic border zone express ICAM-1 (intercellular adhesion molecule-1) and become susceptible to neutrophil toxicity [34]. The leukocyte chemotaxis is also mediated by reactive oxygen trough complement activation, induction of P-selectin expression, chemokine upregulation and the increase of the ability of endothelial ICAM-1 to bind neutrophils [35-41]. Inside of the infracted area, infiltrating leukocytes clear the infarct from dead cells and matrix debris and regulate extracellular matrix metabolism and activate mesenchymal cells through the induction of cytokines and growth factors. TNF-alpha yet expressed at this stage regulates extracellular matrix metabolism by reducing collagen synthesis and by enhancing matrix metalloprotease activity in cardiac fibroblasts [42, 43]. Macrophages and mast cells accumulate in the healing scar and secrete a variety of growth factors and cytokines, inducing fibroblast proliferation. Lymphocytes and a subset of the macrophages produce the macrophage-modulating cytokine IL-10, which may have a role in suppressing the inflammatory response and in tissue remodeling by regulating expression of metalloproteinases and their inhibitors [30]. In the healing wound activated platelets may play multiple roles by aggregating in areas of injury, by contributing to the formation of a fibrin-based provisional matrix and by releasing a variety of chemokines (such as RANTES and PF4), cytokines (such as IL-1 beta) and growth factors (such as platelet-derived growth factor (PDGF) and trasformig growth factor-beta (TGF-beta). In addition, platelets are capable of initiating complement activation and may play a role in localizing the inflammatory response into the area of injury [6, 44-46].

At this stage expression of pro-inflammatory mediators is suppressed, while fibroblasts and endothelial cells proliferate [6]. Inflammatory leukocytes undergo apoptotic death and are cleared from the infarcted area; the removal of "corpses" plays an important role in the resolution of inflammation by inducing the expression of inhibitory mediators, such as TGF-beta and IL-10, which suppress inflammatory cytokine and chemokine synthesis $[6,30,47,48]$.

Fibroblast and endothelial cell proliferation marks the transition from the inflammatory to the proliferative phase of healing [28]. 


\section{HUMORAL PHASE}

It is known that TNF-alpha suppresses cardiac contractility [49, 50] and enhances cardiomyocyte apoptosis [51], and it is expressed in several pathological conditions [52-55]. Moreover TNF-alpha is upregulated in the myocardium in response to transient myocardial ischemia and reperfusion [56-58], but it is also expressed chronically after myocardial infarction.

Indeed TNF-alpha stimulates expression of proinflammatory cytokines, chemokines and adhesion molecules by leukocytes and endothelial cells and regulates extracellular matrix metabolism by reducing collagen synthesis and by enhancing MMP (matrix metallo proteinase) activity in cardiac fibroblasts [42]. These distinct biological effects are mediated through the two different TNFR1 and TNFR2 receptor [6]. The mast cell-derived TNF-alpha rapid release following myocardial ischemia, represents the cytokine responsible for initiating the inflammatory cascade, but also may induce a cytoprotective signal able to preventing or delaying the development of myocyte apoptosis following myocardial infarction [59].

IL-1 is consistently induced and activated following tissue injury and plays an essential role in many inflammatory conditions $[53,60]$. Through activation of the NF- $\kappa$ B system, IL-1 signaling induces the expression of chemokines, pro-inflammatory cytokines [61], adhesion molecules [62], colony-stimulating factors, and mesenchymal growth factor [28]. In different experimental studies marked IL-1 upregulation has been reported in myocardial infarction $[57,63]$. This finding is in agreement with the detection of high IL-1 beta plasma levels in patients with acute myocardial infarction within the first few hours after the onset of chest pain [64]. Through the induction of others chemokine by both mononuclear and endothelial cells and adhesion molecule expression, IL-1 facilitates infiltration of injured tissues by inflammatory leukocytes $[65,66]$. Moreover IL-1 stimulation enhances adhesion molecule expression by endothelial cells and activates integrin-mediated pathways facilitating neutrophil and mononuclear cell transendothelial migration [67, 68], and strongly prolongs neutrophil survival by inhibiting their apoptotic death [69]. Moreover IL-1 signaling may enhance synthesis of other inflammatory mediators promoting cytokine-induced cardiomyocyte apoptosis as demonstrated by both in vitro and in vivo studies [28, 70]. Finally it may increase matrix remodeling of the ventricle, activating protease-induced matrix degradation, altering MMP expression and activity. In addition to its effects on inflammatory cells and cardiomyocytes, IL-1 also modulates phenotype and gene expression of fibroblasts, the main cells involved in reparative responses. IL-1 beta directly enhances fibrous tissue deposition by upregulating the expression of angiotensin II type 1 receptors on cardiac fibroblasts [71] and by stimulating fibroblast migration [72]. These findings suggested that IL-1 signaling is essential for activation of inflammatory and fibrogenic pathways in the healing infarct and may play an important role in the pathogenesis of postinfarction remodeling $[6,73]$.

It is demonstrated that IL-6 was rapidly expressed in the ischemic segments and its expression was dependent upon reperfusion, such as for ICAM-1 [74, 75]. Activation of the inflammatory response in the infracted myocardium is associated with induction of endothelial adhesion molecules and enhanced permeability of the microvasculature. These observations are consistent with the hypothesis that reperfusion initiates a cascade of cytokine-related events leading to IL-6 expression and subsequent induction of ICAM-1 mRNA in the ischemic and reperfused myocardium. IL-6 synthesis is rapidly induced in mononuclear cells and cardiomyocytes of the ischemic myocardium [76-78], in fact in the border zone of myocardial infarcts mononuclear cells and myocytes exhibit reperfusion-dependent expression of IL-6 mRNA within $1 \mathrm{~h}$ after reperfusion [79]. Members of the IL-6 family have profound effects on cardiac myocytes by promoting cardiac hypertrophy, but also by protecting them from apoptosis. TNFalpha of mast cell origin may be a crucial factor in upregulating IL-6 in infiltrating cells and initiating the cytokine cascade responsible for myocyte ICAM-1 induction and subsequent neutrophil-induced injury [80]. Upregulation of chemokines and cytokines results in extravasation of activated bloodderived cells into the infarcted area [6].

The mononuclear infiltration of the myocardium in the first few hours of reperfusion depends on C5a, TGFbeta1 and MCP-1. MCP-1 is rapidly upregulated in the venular endothelium of ischemic myocardial segments [81, 82] and exerts important actions on non-hematopoietic cells, inducing angiogenic and arteriogenic effects [83] and modulating fibroblast phenotype and activity by increasing collagen expression and by regulating MMP synthesis [84]. MCP-1 has important effects on macrophage recruitment and activation, cytokine synthesis and myofibroblast accumulation in healing infarcts. Infiltration of monocytes into the infracted myocardium is followed by maturation and differentiation of these blood - derived cells into macrophages [43]. Previous investigations indicated that MCP-1 induces monocyte IL-1 [85] and IL-6 synthesis [86] and that it may be involved in differentiation of monocytes into foam macrophages [87]. MCP-1 may also directly modulate macrophage differentiation, phagocytic activity and cytokine expression $[6,33]$.

ICAM-1 is a ligand-specific adhesion of the neutrophils to the cardiac myocytes and it is expressed in ischemic myocardial segments. Myocyte ICAM-1 induction could be affected by cytokine IL-1, TNF-alpha and IL-6. ICAM-1 mRNA expression was detected in much of the reperfused viable myocardium by $1 \mathrm{~h}$ of reperfusion, adjacent to areas of the of contraction band necrosis [88]. After $3 \mathrm{~h}$ its expression occurred in cells in the jeopardized area. The area of induction of ICAM-1 mRNA on the viable border zone region of the infarct is the area where the most intense neutrophil margination and infiltration occur [34]. Conversely where reperfusion did not occur, ischemic segments did not express ICAM-1 mRNA or ICAM-1 protein in areas of occlusion for periods up to $24 \mathrm{~h}$. Therefore the layers of myocardial cells directly adjacent to the endocardium are spared injury, conserve glycogen and do not express ICAM-1 mRNA in early reperfusion.

In vitro experiments suggested that the mechanism of neutrophil-cardiomyocyte adhesion is dependent not only on expression of ICAM-1, but also on CD18 integrin activation on neutrophils [89], by injured cardiomyocytes. Integrins are a family of heterodimeric membrane glycoproteins that con- 
sist of an alpha and beta subunit. Activation of integrin CD18 is required for the firm adhesion of neutrophils. Stationary neutrophils adherent to the luminal andothelial surface frequently change shape and assume the characteristic bipolar configuration of motile cells $[90,91]$.

Another important role in neutrophil chemotaxis in the infarcted myocardium is determined by the chemokine IL-8 that may play an important role in granulocyte recruitment in the infarcted myocardium and has angiogenic properties in the ischemic heart [92]. IL-8 induces the neutrophil respiratory burst and granule release, and enhances cellular adhesion. In reperfused myocardial infarcts, IL- 8 is markedly induced after $1 \mathrm{~h}$ of reperfusion and persists at high levels beyond $24 \mathrm{~h} \mathrm{[6].}$ Several studies using antibody neutralization have supported an important role for IL-8 in mediating neutrophil - induced injury in ischemic and reperfused tissue.

Finally, the IL-10, produced by macrophages is the "stop signal" to the inflammatory phase. It is a mononuclear cell product and modify function, morphology and phenotype of monocyte-macrophages and inhibits the production of IL-1 alpha and beta, TNF-alpha, IL-6, IL-8, suppressing the inflammatory response [93, 94]. IL-10 mRNA and protein upregulation was demonstrated in the reperfused infarcted myocardium using a canine model of myocardial infarction. IL-10 expression was first detected at $5 \mathrm{~h}$ and peaked following 96-120 h of reperfusion. It also regulates extracellular matrix metabolism and angiogenesis $[48,94]$.

\section{CELLULAR PHASE}

Neutrophils are recruited very early after cardiac injury and the selectin family of adhesion molecules mediates their transmigration, in the infarcted myocardium. Moreover selectins promote leukocyte attachment and rolling at shear stresses characteristic of post-capillary venules [6]. Indeed after an inflammatory stimulus, leukocytes roll along the post-capillary venules at velocities distinctly below that of flowing blood and determine a microvascular obstruction. Some rolling cells after stops change shape in apparent response to local chemotactic stimuli after a few minutes [34]. Moreover neutrophils may directly injure parenchymal cells through release of specific toxic products [95] and may contribute to the healing response through their apoptosis and subsequent clearance by macrophages, resulting in resolution of inflammation and transition to fibrosis [6].

Differentiated macrophages play multiple roles in the healing infarct. First, they are responsible for phagocytosis of dead cells and debris and for clearance of apoptotic neutrophils and cardiomyocytes. Second, they serve as a source of cytokines and growth factors regulating fibroblast growth and angiogenesis. Third, they contribute to extracellular matrix remodeling by producing MMPs and their inhibitors [6].

Mast cells are multifunctional resident cells, capable of secreting a wide range of inflammatory and pro-fibrotic mediators. They play a dual role by acting both in the early phase and then in the late inflammation. It is demonstrated that resident cardiac mast cells rapidly degranulate following infarction releasing large amounts of preformed histamine and TNF-alpha, modulating the inflammatory response [80]. Histamine may induce surface expression of P-selectin in endothelial cells, whereas mast cell-derived TNF-alpha played an important role in stimulating cytokine expression by infiltrating mononuclear cells and regulating adhesion molecule expression and leukocyte recruitment. These resident mast cells are predominantly located in close proximity to vessels [96].

In later stages, there is a likely role for mast cells in the orchestrated interaction of cells, cytokines, growth factors and extracellular matrix proteins mediating myocardial repair and participate in the fibrotic process. Recent studies demonstrated that mast cell numbers increase in the healing phase of reperfused canine myocardial infarcts [97]. Tryptase released from mast cell granules stimulates granulocyte recruitment [98], and upregulates cytokine and chemokine synthesis [99, 100] and induces fibroblast proliferation [101] and chemotaxis and upregulates type I collagen production [102]. Histamine has been shown to stimulate fibroblast growth and collagen synthesis in vitro [103]. Furthermore, mast cells are important sources of TGF-beta, basic fibroblast growth factor (bFGF), and vascular endothelial growth factor (VEGF), factors that can regulate fibroblast growth, modulate extracellular matrix metabolism and stimulate angiogenesis [6, 104-106].

The increase in mast cell density was first noted after 72 $\mathrm{h}$ of reperfusion. Following 5-7 days of reperfusion, mast cell numbers in fibrotic areas, in which myocytes were fully replaced by scar, were markedly higher than the numbers from areas of the same section showing intact myocardium $[34,97]$.

\section{PROTEINS AND CELLS IDENTIFICATION AND THEIR TOPOGRAPHIC DISTRIBUTION}

The data reported regarding the production and function of numerous cytokines, chemokines, adhesion molecules and cells produced in response to myocardial infarction, derived mainly from animal and human studies, in vivo and in vitro, by means of the use of techniques designed to detect the mRNA as an index of their expression.

Additional data, and not always match, especially as regards the timing of expression of various cytokines, can be supplied by research with western blotting of the real presence of the proteins in the sample examined.

ICAM-1 is expressed $1 \mathrm{~h}$ after reperfusion with marked elevations after longer time intervals. These data derived using in situ hybridization techniques, which demonstrated ICAM-1 RNA expression at $24 \mathrm{~h}$ mRNA was found in all myocardial samples suggesting that circulating cytokines are inducing ICAM-1 mRNA in normal as well as in ischemic areas. However, when the ICAM-1 protein is searched, it is not seen until 3-6 $\mathrm{h}$ and is almost exclusively seen in the ischemic area at all time points [107].

In a work of Bujak et al. [73] they studied western blotting protein isolated from infarct and non-infarcted remodeling myocardium of (wild type) and IL1R1-null hearts after 7 days of reperfusion, using a goat anti-MMP2 and rat anti MMP-3 antibody. They demonstrated that IL-1Rl deficiency was associated with reduced MMP-2 and MMP-3 protein levels in the infracted myocardium. So the IL-1Rl deficiency altered the MMP:TIMP (tissue inibitors of metallo protein- 
ase) expression profile in the infarct and the remote remodeling heart reducing MMP-2 and 3 expression. IL-1 beta directly enhances fibrous tissue deposition by up-regulating expression of angiotensin II type 1 (AT1) receptors on cardiac fibroblasts [71] and by stimulating fibroblast migration [72]. Beyond its proinflammatory and fibrogenic properties, IL-1 also promotes extracellular matrix remodeling by enhancing cardiac fibroblast MMP expression [42].

Western blotting was used by Oyamada et al. [108] to study chymase, vibronectin and fibronectin protein expression after acute myocardial ischemia/reperfusion compared with non-ischemic myocardial tissue. They demonstrate that chymase inhibition plays an important roles in myocardial protection through MMP-9, inflammatory markers and the eNOS pathway and may attenuate fibrosis induced by activated chymase after acute myocardial infarction - reperfusion.

Kratzschmar et al. (1996) investigated with western blotting the expression of ADAM-15 in rat MI (myocardial infarction) and elucidated its possible mechanisms in the pathological process of MI. A disintegrin and metalloproteases (ADAMs) are a large family of membrane-bound glycoproteins, which consist of prodomain, metalloprotease domain, disintegrin domain, cysteine-rich domain, epidermal growth factor (EGF)-like domain, transmembrane domain, and cytoplasmic domain. It will provide a novel insight into the mechanisms, which influence the inflammatory response and cardiac remodelling following MI [109, 110].

As an example of application of the western blotting also for the study of cell populations, $\mathrm{Hu} \mathrm{Y}$ et al. demonstrate for the first time that SR-A (scavenger receptor) deletion promotes macrophage polarization toward a skewed M1 phenotype after myocardial infarction. Their results suggest that SR-A-dependent M1 macrophage polarization may become a new therapeutic target for healing and ventricular remodeling after MI. Monocytes/macrophages display heterogeneity in both mouse and human. In mouse, macrophages can be categorized into at least two phenotypically and functionally distinct subsets, i.e., classically (M1) and alternatively (M2) activated macrophages. Priming with interferon-c (IFN-c), TNF-alpha, or sub-stimulatory concentrations of lipopolysaccharide (LPS) will program macrophages into the M1 phenotypic state, which is characterized by a strong proinflammatory profile and potent bacterial killing. In contrast, exposure to IL-4 or IL-13 generates M2 macrophages, which display an attenuated proinflammatory and an enhanced antiinflammatory response. Class A scavenger receptor plays a key role in the inflammatory response by modulating the activity of inflammatory cytokines [111].

Once demonstrated the presence of proteins (cytokines, chemokines, etc.) is important to know the topographical distribution, obtaining in this way additional information regarding the extension of the inflammatory process in function of the time stayed from the time of myocardial infarction.

It has been proved that TNF-alpha can be produced by a variety of different cell types in the myocardium and in several sites. In their work Irwin et al. [56] examined both the temporal and spatial expression of TNF-alpha in a chronic model of cardiac injury with northern blot analysis and immunohistochemistry. They found that TNF-alpha is persistently expressed in the myocardium after infarction, and that its expression was not limited to the infarct zone but was persistently expressed by myocytes in the controlateral normal zone, in which myocardial remodeling was ongoing. They demonstrated that TNF-alpha upregulation occurs very early after myocardial injury released from mast-cells and persists in myocytes with time. The fact that TNF-alpha gene and protein expression is at a high level in the controlateral zone suggests a potential role of the cytokine in the signaling process leading to myocardial remodeling.

By observation with confocal microscope we studied the localization and the intensity of fluorescence in the different areas of myocardium of TNF- $\alpha$, IL- $1 \beta$ and IL- 6 induced by ROS.

The preliminary results of our study involving fatal cases of myocardial infarction, we observed, using both western blotting that the confocal microscope, a different expression over time of inflammatory cytokines (IL-1beta, IL-6, IL-8, TNF-alpha, MCP-1, ICAM-1, CD18, IL-15), neutrophils and mast cells, in the first 12 hours after the onset of myocardial infarction (Figs. 1-4). All these cytokines are oversynthesized mainly by necrotic cardiomyocytes and activated macrophages and neutrophiles in damaged areas. They have direct effects on cardiomyocytes and down-regulate sarcoplasmatic reticulum proteins, inhibit contractility and induce apoptosis [53]. Final biological effect of action of cardioinhibitory cytokines depends on the degree and duration of their upregulation. Mild elevation or even high but short-lasting may be protective, but exaggerated and prolonged increase in cardioinhibitory cytokines may lead to irreversible cardiac injury and promote development of heart failure [53].

The induction and release of cytokine such as TNF-alpha and IL- 6 are rapidly release in the central zone during a myocardial infarction; however they are usually maximal in the border zone $[56,79]$.

Using the double labeling is possible to observe the colocalization of cytokines in the myocytes, as the authors have done in this paper where they sought to determine whether IL-6 modulates myocardial infarction or the late phase of preconditioning. Colocalization of IL-6 and troponin T signals by confocal microscopic examination confirmed the cytoplasmic distribution of intracellular IL-6 in cardiomyocytes. IL-6 plays an obligatory role in late preconditioning via JAK-STAT signaling (Janus kinase-signal trasducers and activators of transcription) and upregulation of iNOS and COX-2 (cyclooxygenase) [112].

The ability to acquire, to keep, to work with images such as those obtained with confocal microscopy, to perform $3 \mathrm{D}$ reconstruction, to produce optical sections of the same sample, and the excellent definition of the image, using fluorescence all provide knowledge and ideas for further research. This non-invasive technique also permits characterization, localization and qualitative quantification of free ions, messengers, $\mathrm{pH}$, voltage and other molecules constituting living cells [113]. 


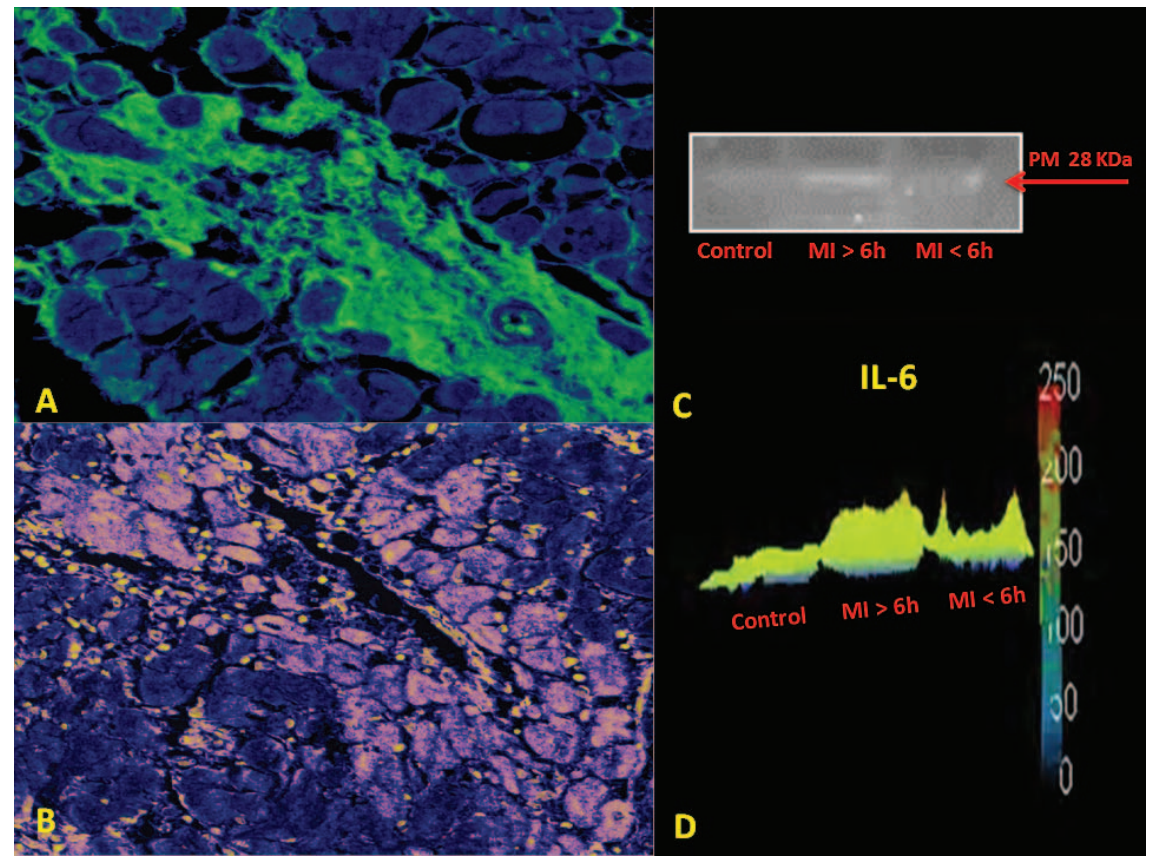

Fig. (1). (A+B) Confocal laser scanning microscope to observe IL-6 topographic distribution in myocardial infarction (MI): (A) little foci of myocardial necrosis $(<6 \mathrm{~h}$ ) with weak perivasal and interstitial IL-6 reaction (green reaction); (B) foci of myocardial necrosis $(>6 \mathrm{~h})$ with intensive expression of IL-6 by intact myocytes of the border zone (pink reaction). (C) Immunoblot analysis demonstrated the presence of IL6 , with a molecular weight of approximately $28 \mathrm{kDa}$, obtained from the cardiac tissue. (D) A graphic overview of results based on the light intensity and the number of pixels detected.

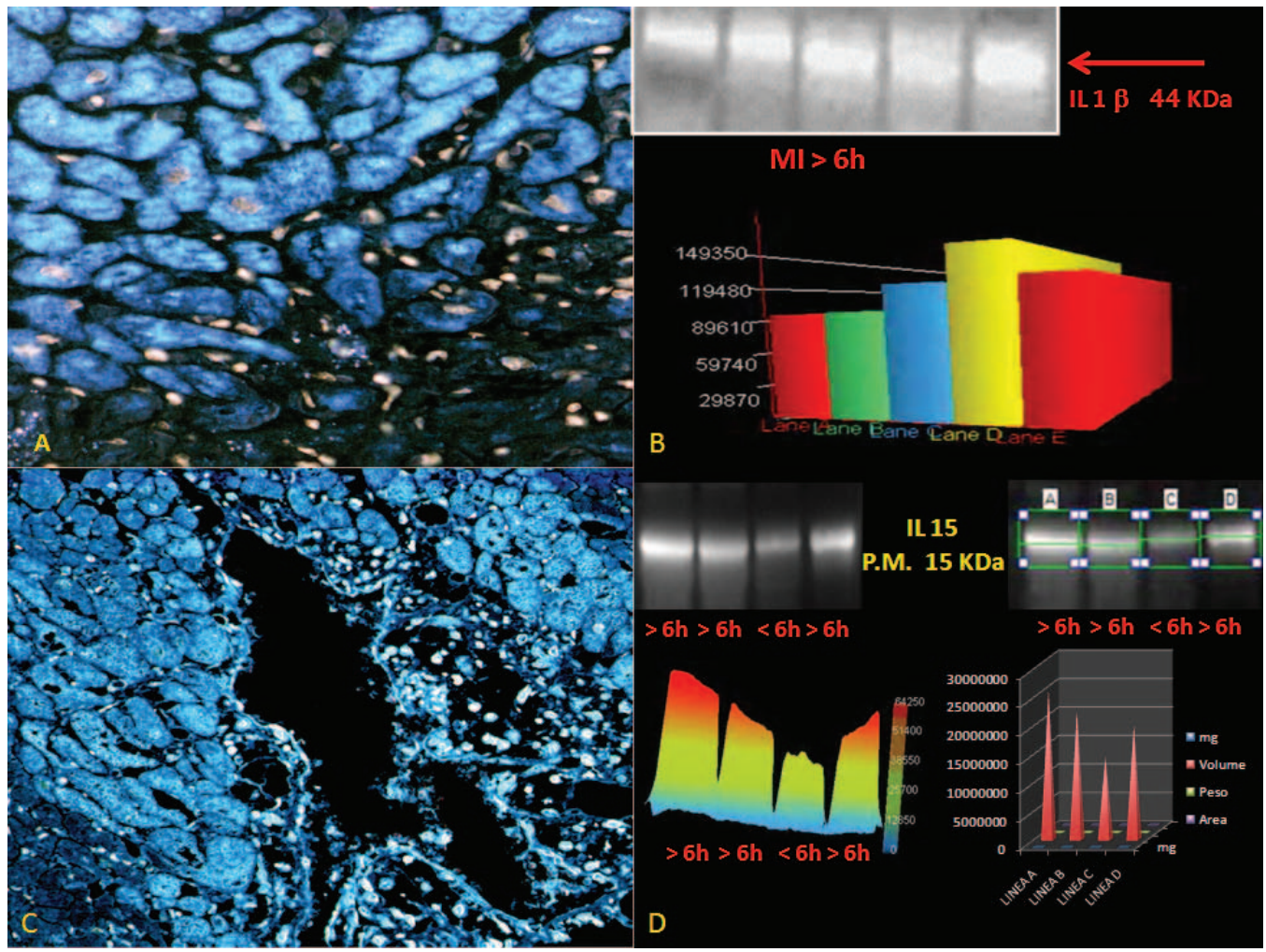

Fig. (2). (A) Confocal laser scanning microscope. Strong positive IL-1beta reaction (in blue) of myocytes near foci of myocardial necrosis (> 6h). (B) Western blotting analysis demonstrated the presence of IL-1beta with a molecular weight of approximately 44kDa, obtained from cardiac tissue with myocardial infarction lasting more than 6 hours. (C) Confocal laser scanning microscope. Strong positive IL-15 perivasal reaction (in blue) of myocytes near foci of myocardial necrosis $(>6 \mathrm{~h})$. (D) Immunoblot analysis demonstrated the presence of IL-15, with a molecular weight of approximately $15 \mathrm{kDa}$, obtained from the cardiac tissue and the graphic overview of results based on the light intensity and the number of pixels detected, which shows a different intensity between myocardial lasting shorter than 6 hours compared to that of time greater than 6 hours. 


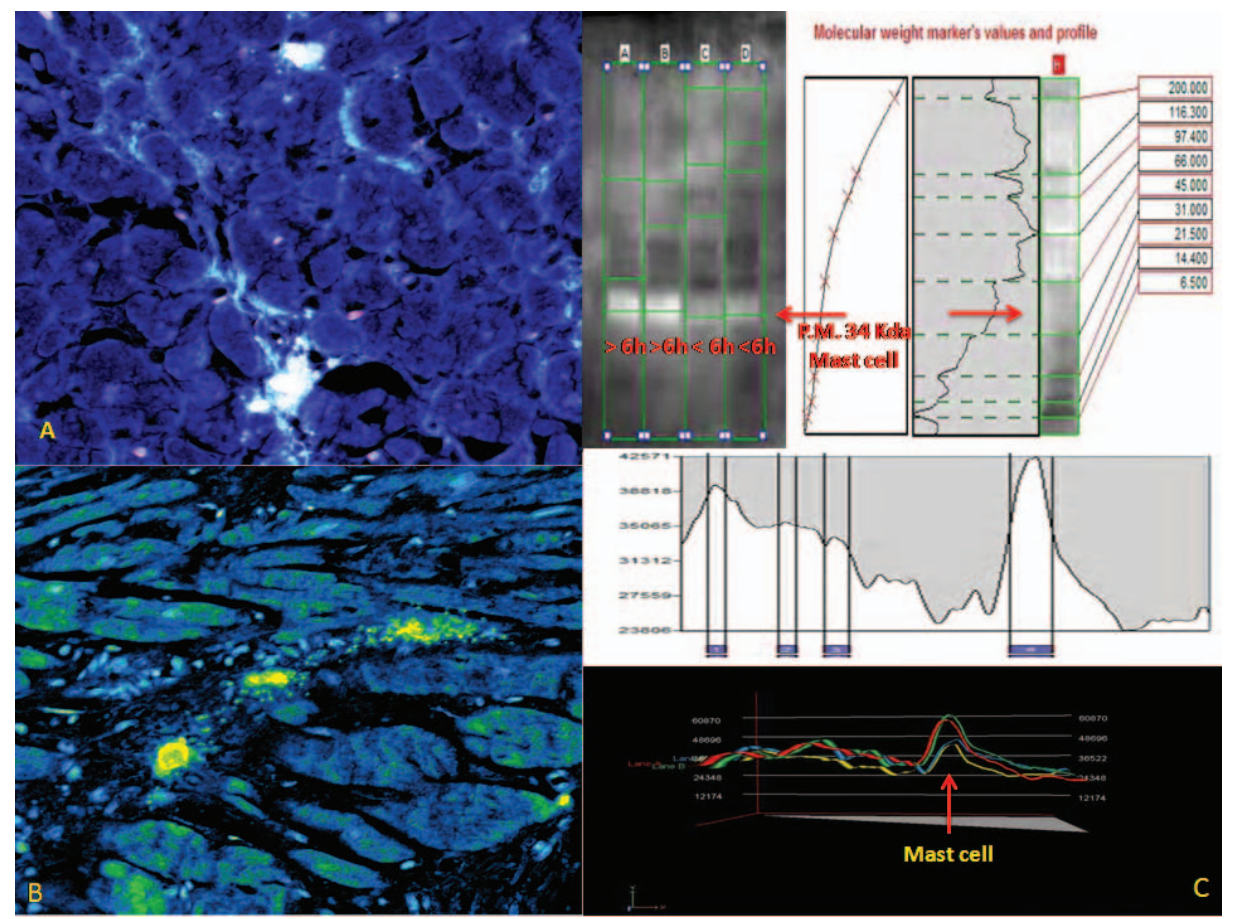

Fig. (3). $(A+B)$ Confocal laser scanning microscope to observe mast cells topographic distribution in myocardial infarction (MI): (A) interstitial mast cells (white reaction) in early myocardial infarction $(<6 \mathrm{~h})$. $(\mathbf{B})$ perivasal degranulated mast cells (green reaction) near foci of myocardial necrosis $(>6 \mathrm{~h})$. (C) The different subsequent steps of the analysis by western blotting: from the electrophoresis in polyacrylamide gels, the identification of the band of interest based on of the comparison with the standard of molecular weights, up to the graphics processing.

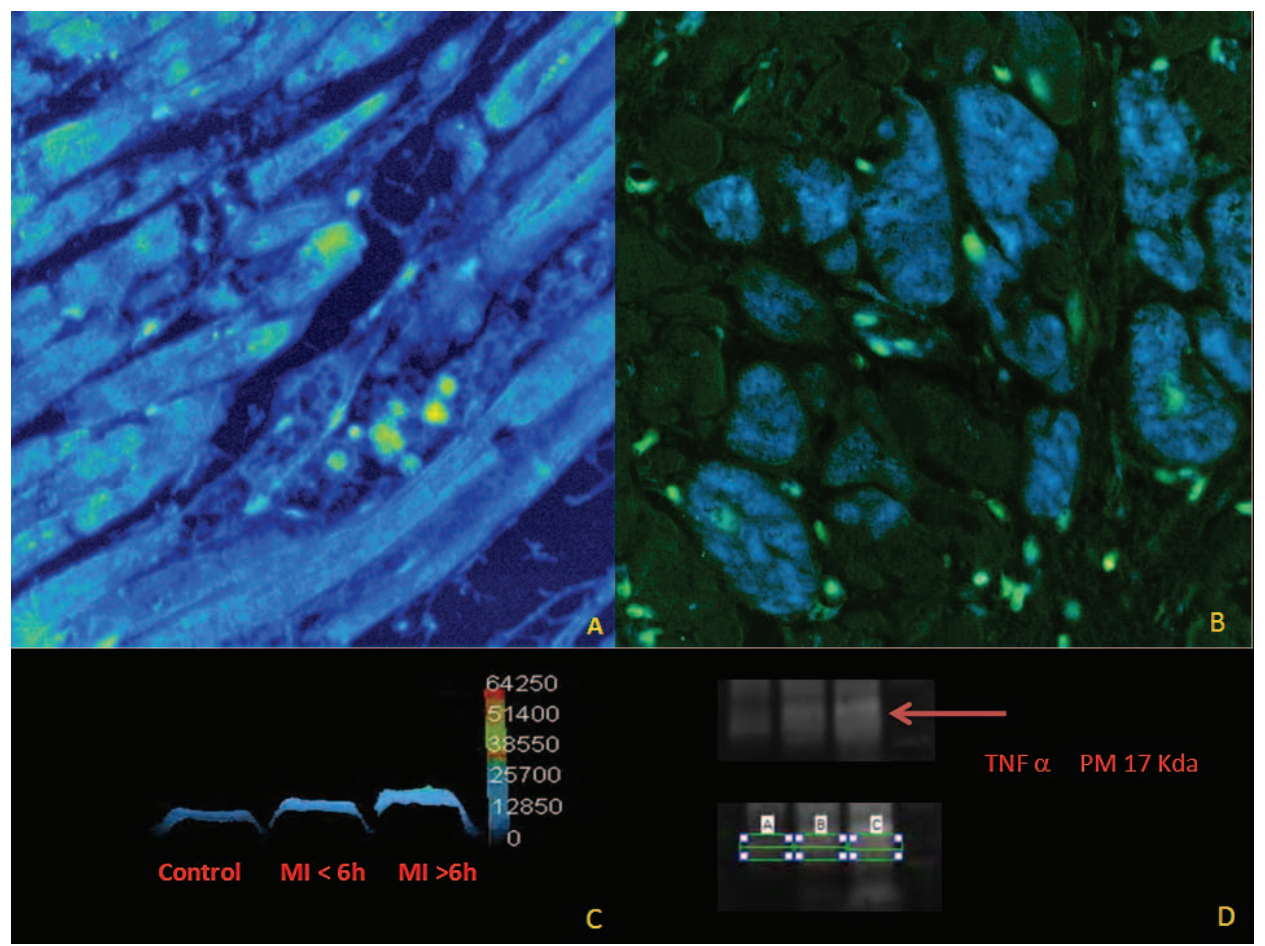

Fig. (4). (A+B) Confocal laser scanning microscope to observe TNF-alpha topographic distribution in myocardial infarction (MI): (A) little foci of myocardial necrosis $(<6 \mathrm{~h})$ with weak TNF-alpha reaction (in green); (B) more extensive intensive expression of TNF-alpha (blue reaction) by intact myocytes of the border zone near foci of myocardial necrosis $(>6 \mathrm{~h})$. (C) Immunoblot analysis demonstrated the presence of TNF-alpha, with a molecular weight of approximately $17 \mathrm{kDa}$, obtained from the cardiac tissue. (D) A graphic overview of results based on the light intensity and the number of pixels detected, showing the differences between myocardial lasting shorter than 6 hours compared to that of time greater than 6 hours. 
Although several studies have suggested a role for mast cells in infarct healing, their specific contribution to the cellular events associated with post-infarction inflammation and scar formation remains unclear. In fact, many mast cellderived mediators can also be secreted by other cell types, which are present in the infarcted ventricle (macrophages, fibroblasts, and lymphocytes). Two population of mast cells are individuated by Frangogiannis [80] with an histochemical techniques identifying intracytoplasmatic granules: "typical" mast cells or connective-tissue-type mast cells, which stained with toluidine blue regardless of fixation, and "atypical" mast cells or mucosal-type mast cells that exhibited metachromasia only after fixation in Carnoy's or Mota's fixative. Then with double-labeling studies combining fluorescent immunocytochemistry for TNF- $\alpha$ and FITC-avidin counterstaining showed granular cytoplasmic TNF- $\alpha$ immunoreactivity to be confined almost exclusively to FITCavidin-labeled mast cells. Mast cells in the ischemic and reperfused myocardium showed significant degranulation. In contrast, mast cells in normally perfused segments or in controls appeared to be fully granulated. Immunostaining for TNF- $\alpha$ in ischemic sections after 1 hour of coronary occlusion and 3 hours of reperfusion showed that TNF- $\alpha$ immunoreactivity was localized predominantly in mast cells. Some of the TNF- $\alpha$-positive cells in the ischemic segments showed evidence of degranulation, whereas all the mast cells in the normally perfused tissue samples appeared to be fully granulated. Similar immunohistochemical experiments using an antibody to IL-1 $\beta$ demonstrated no IL- $1 \beta$ immunoreactivity in the control canine heart. No significant IL-1 $\beta$ expression was noted in the ischemic heart in early reperfusion.

Somasundaram et al. [100] examined the time-course of mast cell and macrophage infiltration in healing canine infarcts using the dual fluorescence for studying of the granules. They demonstrate that, although macrophages are much more numerous than mast cells in the infarcted heart during the proliferative phase of healing, mast cell density remains elevated in mature infarcts, while the number of macrophages significantly decreases. Then identify tryptase and chymase activity and demonstrated the presence of tryptase and chymase in most canine cardiac mast cells. Mast cells in non-infarcted areas of the canine heart were elongated perivascular cells with a high granular content. Mast cells in infarcted and non-infarcted segments of the canine heart had both alcian blue-positive and safranin-positive granules. Mast cells in control and infarcted areas contained both chymase and tryptase at all stages of infarct healing.

In other studies the ability of the confocal microscope has been used to detect the fine structures of myocytes both in normal conditions (distribution of structural proteins, $\mathrm{Z}$ disks, etc.) and especially in the presence of pathological alterations (e.g. contraction band necrosis) with imaging possibilities that were unthinkable until a few years ago [55, $114,115]$ as well as the ability to visualize intracellular $\mathrm{Ca} 2+$ deposits [116].

Li et al. studied the effects of TNF-alpha on calcium movement in rat ventricular myocytes. Intracellular free $\mathrm{Ca} 2+$ concentration was measured with calcium fluorescent probe Fluo-3/AM and laser confocal microscope. TNF-alpha inhibited $\mathrm{I}(\mathrm{Ca}, \mathrm{L})$ in rat ventricular myocytes, while increas- ing the intercellular free $\mathrm{Ca} 2+$ level due to the release of $\mathrm{Ca} 2+$ from intracellular stores. This phenomena indicates TNF-alpa must participates in other signal transduction gateways to induce intracellular free $\mathrm{Ca} 2+$ release from sarcoplasmic reticulum [117].

Another important application is represented by measurement of fluorescence intensity in cardiomyocytes, also in small well-defined volumes in single cells. This method consents the comparison of fluorescence from different cells for the same proteins, with a quantitative method [118].

Another confocal microscopy studies are conducted to detect and identify apoptotic cell in both MI and not-MI, using apoptosis detection kit (Tunel). In order to identify apoptotic cell type, the sections were double stained for cardiomyocytes (Troponin T) and macrophage detection. They found that apoptotic macrophages were barely detected in the acute phase of reperfusion (2.5h-R) whereas they were most abundant from 1d-R. In contrast, apoptotic cardiomyocytes were already detected at $2.5 \mathrm{~h}-\mathrm{R}$. Moreover the progression of Tunel + cell and infarct size over time shows that necrosis stars during ischemia and increases proportional to the severity of ischemia whereas apoptosis in triggered during reperfusion [7].

Apoptosis rate may be also assayed by flow cytometry. In their work flavoprotein fluorescence was scanned by confocal laser microscope to assess the mitochondrial ATPsensitive potassium (mitoKATP) channel activity. Wang et al. found that myocardial cell apoptosis occurs in hypoxia/reoxygenation injury, and EPO (erythropoietin) can protect rat cardiomyocytes from hypoxia/reoxygenationinduced apoptosis. The protective effect is partly associated with the PKC/mitoKATP (protein kinase $\mathrm{C} /$ mithocondrial ATP) pathway [119].

Another study was conducted to study the spatiotemporal changes of gap junctions (connexin 43), desmosomes (desmoplakin), adherens junctions (cadherin) and integrins (beta 1 integrin) in cardiomyocytes by immunoconfocal microscope at border zone of myocardial infarction in rats. Matsushita and coworkers found that remodeling of gap junctions after myocardial infarction is closely related to changes in desmosomes and adherens junctions and that remodeling of the intercalated disk region at the myocardial interface with areas of scar tissue is associated with acquisition of laminin and $\beta 1$-integrin. Moreover the results showing that abnormal distribution of cell junctions occurred at both borderline cardiomyocytes (in contact with scar tissues) and vicinity cardiomyocytes (not in contact with scar tissues), suggest that direct contact with the scar tissue is not essential to cause the abnormality, but rather, indirect effects such as ischemia may cause the abnormality [3, 120].

Communication between myocytes, fibroblasts, and endothelial cells, as well as the extracellular matrix, are critical in heart composition and function during normal development and pathology. It is known that cytokines play a role in cell-cell signaling in the heart. Bowers et al. used confocal and transmission electron microscopy to observe close relationships and possible direct communication between these cells in vivo. They observed with confocal microscopy a close association between cardiac fibroblasts and the capillaries of the heart. Indeed, they found that interactions be- 
tween myocytes and cardiac fibroblasts results in increased interleukin-6 and tumor necrosis factor- $\alpha$ secretion [121].

Developing a Raman confocal microscope incorporating slit-scanning apparatus, on the hypothesis that high-contrast imaging is possible by using a high-speed Raman microscope combined with resonance effect, Ogawa et al. tried to visualize heart tissue components based on the molecular composition without staining. The method of particular line illumination and parallel detection system shortened the image acquisition time, from hours to minutes. Spontaneous Raman microscopy (SRM) provides specific vibrational signatures of chemical bonds as a spectrum, allowing identification of particular molecules without labeling. The Raman spectra usually exhibit sharp spectral features based on specific molecular structures and conformations of tissues. This makes SRM very useful for biomedical applications, such as quantitative histochemical analysis of atherosclerosis. However, these Raman spectroscopic studies are not generally based on precise tissue imaging. Tissue imaging clarifies the distribution of cellular components in tissues, and is indispensable for morphometric analysis of a given tissue. By using in this way they show that SRM provides not only morphological but also biochemical information regarding heart tissue. They found that the Raman spectrum obtained from fibrotic tissue was highly consistent with that of pure chemical collagen type I. These data are in accordance with previous studies, which that have revealed that after myocardial infarction necrotic cardiomyocytes are eventually replaced by fibrotic tissues consisting mainly of collagen type I [122].

Raman spectroscopy was used for chemical analysis of intact human coronary artery and atherosclerotic lesions, to study cellular and extracellular components in different stage of disease progression [123, 124]. Clear differences in the surface biochemical morphology were observed between healthy artery wall, early atherosclerotic lesions, and advanced plaques. In particular, differences in collagen fibril structures were noted between early and advanced lesions. Such changes in collagen morphology detected by SHG may provide a clinical measure for differentiating plaque burden [125].

\section{CONCLUSION}

Inflammatory pathways play an essential role in the pathogenesis of adverse remodeling by modulating the qualitative characteristics of the scar, altering the composition of the extracellular matrix, and mediating fibrous tissue deposition in the infarct border zone and the non infracted areas [29].

Because timing of anti-inflammatory interventions and patient selection will be critical to the success of antiinflammatory interventions after myocardial infarction, large animal models and advanced imaging technologies will be crucial before making the transition to clinical application [126].

Although there are numerous studies about the expression of various cytokines based mainly on mRNA detection methods, it becomes necessary to confirm or integrate these data by western blotting. Since there is always an exact match between the mRNA expression and its transcription into protein, it is essential to check the presence of proteins in the sample by semi quantitative analysis by western blotting.

These methods may be useful to study and define the expression of a wide range of inflammatory mediators at several different timepoints providing a more detailed analysis of the time course the infarct.

As seen some cytokines, chemokines and inflammatory cells undergo to quantitative and/or spatial changes after myocardial infarction. Such differences are well appreciated by microscopic observation of tissue sections stained with specific immunohistochemical reactions, or by western blotting able to detect the real presence of the protein in a specific sample. As demonstrated in some studies, mRNA expression detected by in situ hybridization techniques, does not match the effective presence of the proteins (e.g., ICAM1), demonstrating a protein latency expression that should be important to consider when evaluating the time of onset of myocardial infarction.

The combined use of western blotting and confocal microscope allows detecting the presence of proteins in the sample and trying to observe the exact location within the tissue, or the topographical distribution of the same.

These methods can be used in the post-mortem diagnosis of myocardial infarction, providing useful information on the expression over time of several cytokines, chemokines and cells, and their quantification. This aspect is important in considering the fact that although animal models provide important information in dissecting pathophysiologic mechanisms, their ability to predict the success of a specific approach in human patients is limited. The complexity of the clinical context cannot be simulated by experimental studies the postinfarction inflammatory cascade is dependent on a complex network of molecular mediators with pleiotropic effects, dictated by contextual factors and by critical spatial and temporal variables [127].

Western blotting, confocal laser scanning microscope are useful tools to study the progressive changes occur in viable myocardium (myocytes death, inflammatory response, connective tissue changes). Combining Raman imaging and other analytical techniques is expected to yield further powerful insight from the data, and can potentially be used as a tool for identifying physiological changes related to myocardial infarction.

\section{CONFLICT OF INTEREST}

The authors confirm that this article content has no conflict of interest.

\section{ACKNOWLEDGEMENTS}

Declared none.

\section{REFERENCES}

[1] Korb G, Totović V. Electron microscopical studies on experimental ischemic lesions of the heart. Ann N Y Acad Sci 1969; 156(1): 4860 .

[2] Hort W. Microscopic observations on human myocardial infarction. Virchows Arch A Pathol Pathol Anat 1968; 345(1): 61-70. 
[3] Matsushita T, Oyamada M, Fujimoto K, et al. Remodeling of cellcell and cell-extracellular matrix interactions at the border zone of rat myocardial infarcts. Circ Res 1999; 85(11): 1046-55.

[4] Baroldi G. Basic pathophysiological changes. In: Fineschi V, Baroldi G, Silver MD, Eds. Pathology of the heart and sudden death in forensic medicine. CRC Press/Taylor \& Francis: Boca Raton, FL 2006; pp. 41-3.

[5] Frangogiannis NG. The mechanistic basis of infarct healing. Antioxid Redox Signal 2006; 8(11-12): 1907-39.

[6] Frangogiannis NG. The immune system and cardiac repair. Pharmacological Research 2008; 58(2): 88-111.

[7] Vilahur G, Juan-Babot O, Peña E, Oñate B, Casaní L, Badimon L. Molecular and cellular mechanisms involved in cardiac remodeling after acute myocardial infarction. J Mol Cell Cardiol 2011; 50(3): 522-33.

[8] Pawley JB. The handbook of biological confocal microscopy, 3rd ed. Plenum Press: New York 2006.

[9] Boyde A. Bibliography on confocal microscopy and its applications. Scanning 1994; 16: 33-56.

[10] Turillazzi E, Karch SB, Neri M, Pomara C, Riezzo I, Fineschi V. Confocal laser scanning microscopy. Using new technology to answer old questions in forensic investigations. Int J Legal Med 2008; 122(2): 173-77.

[11] Lichtman JW. Confocal microscopy. Sci Am 1984; 271: 40-45.

[12] Wilson T, Sheppard CJR. Theory and practice of scanning optical microscopy. Academic Press: London 1984.

[13] White JG, Amos WB, Fordham M. An evaluation of confocal versus conventional imaging of biological structures by fluorescence light microscopy. J Cell Biol 1987; 105(1): 41-8.

[14] Minsky M. Memoir on inventing the confocal scanning microscope. Scanning 1988; 10: 128-38.

[15] Diaspro A. Confocal and two-photon microscopy: foundations, applications, and advances. Wiley-Liss, New York: 2001.

[16] Amos WB, White JG. How the confocal laser scanning microscope entered biological research. Biol Cell 2003; 95(6): 335-42.

[17] Towbin H, Staehelin T, Gordon J. Electrophoretic transfer of proteins from polyacrylamide gels to nitrocellulose sheets: procedure and some applications. 1979. Biotechnology 1992; 24: 145-9.

[18] Hayes PC, Wolf CR, Hayes JD. Blotting techniques for the study of DNA, RNA, and proteins. BMJ 1989; 299(6705): 965-8.

[19] Bolt M, Mahoney P. High-efficiency blotting of proteins of diverse sizes following sodium dodecyl sulfate-polyacrylamide gel electrophoresis. Anal Biochem 1997; 247(2): 185-92.

[20] Burnette WN. "Western Blotting": Electrophoretic transfer of proteins from sodium dodecyl sulfate--polyacrylamide gels to unmodified nitrocellulose and radiographic detection with antibody and radioiodinated protein A. Anal Biochem 1981; 112(2): 195-3.

[21] Harlow E, Lane D. Antibodies: A Laboratory Manual. Cold Spring Harbor Laboratory Press: Cold Spring Harbor, NY 1988.

[22] Sambrook J, Fritsch EF, Maniatis T. Molecular Cloning: A Laboratory Manual, Cold Spring Harbor Laboratory Press: Cold Spring Harbor, NY 1989.

[23] Towbin H, Gordon J. Immunoblotting and dot immunobinding-current status and outlook. J Immunol Methods 1984; 72(2): 31340.

[24] Wadsworth JD, Joiner S, Hill AF, et al. Tissue distribution of protease resistant prion protein in variant Creutzfeldt-Jakob disease using a highly sensitive immunoblotting assay. Lancet 2001; 358(9277): 171-80.

[25] Chalmers JM, Edwards HGM, Hargreaves MD. Infrared and Raman Spectroscopy in Forensic Science. John Wiley \& Sons, Ltd: Chichester, UK 2012.

[26] Treado PJ, Priore RJ, Nelson MP. Raman Spectroscopic Imaging. In: Applications of Vibrational Spectroscopy in Food Science, vol. 1, John Wiley \& Sons, Ltd: Chichester, UK 2010; pp. 167-94.

[27] Treado PJ, Levin IW, Lewis EN. Near-infrared acousto-optic filtered spectroscopy: a solid state approach to chemical imaging. Appl Spectrosc 1992; 46 (4): 553-9.

[28] Bujak M, Frangogiannis NG. The role of Interleukin-1 in the pathogenesis of heart disease. Arch Immunol Ther Exp (Warsz) 2009; 57(3): 165-76

[29] Hill JH, Ward PA. The phlogistic role of C3 leukotactic fragments in myocardial infarcts of rats. J Exp Med 1971; 133(4): 885-900.

[30] Dobaczewski M, Gonzalez-Quesada C, Frangogiannis NG. The extracellular matrix as a modulator of the inflammatory and repara- tive response following myocardial infarction. J Mol Cell Cardiol 2010; 48(3): 504-11.

[31] Bolli R, Marbán E. Molecular and cellular mechanisms of myocardial stunning. Physiol Rev 1999; 79(2): 609-34.

[32] Frangogiannis NG, Entman ML. Targeting the chemokines in myocardial inflammation. Circulation 2004; 110(11): 1341-2.

[33] Frangogiannis NG. Chemokines in ischemia and reperfusion. Thromb Haemost 2007; 97(5): 738-47.

[34] Frangogiannis NG, Smith CW, Entman ML. The inflammatory response in myocardial infarction. Cardiovase Res 2002; 53(1): 3147.

[35] Granger DN. Role of xanthine oxidase and granulocytes in ischemia-reperfusion injury. Am J Physiol 1988; 255(6 Pt2): H1269-75.

[36] Shingu M, Nobunaga M. Chemotactic activity generated in human serum from the fifth component of complement by hydrogen peroxide. Am J Pathol 1984; 117(2): 201-6.

[37] Akgür FM, Brown MF, Zibari GB, et al. Role of superoxide in hemorrhagic shock-induced P-selectin expression. Am J Physiol Heart Circ Physiol 2000; 279(2): H791-7.

[38] Patel KD, Zimmerman GA, Prescott SM, McEver RP, McIntyre TM. Oxygen radicals induce human endothelial cells to express GMP-140 and bind neutrophils. J Cell Biol 1991; 112(4): 749-59.

[39] Lakshminarayanan V, Drab-Weiss EA, Roebuck KA. H2O2 and tumor necrosis factor-alpha induce differential binding of the redox-responsive transcription factors AP-1 and NF-kappaB to the interleukin-8 promoter in endothelial and epithelial cells. J Biol Chem 1998; 273(49): 32670-8.

[40] Lakshminarayanan V, Beno DW, Costa RH, Roebuck KA. Differential regulation of interleukin-8 and intercellular adhesion molecule- 1 by $\mathrm{H} 2 \mathrm{O} 2$ and tumor necrosis factor-alpha in endothelial and epithelial cells. J Biol Chem 1997; 272(52): 32910-8.

[41] Sellak H, Franzini E, Hakim J, Pasquier C. Reactive oxygen species rapidly increase endothelial ICAM-1 ability to bind neutrophils without detectable upregulation. Blood 1994; 83(9): 2669-77.

[42] Siwik DA, Chang DL, Colucci WS. Interleukin-1beta and tumor necrosis factor-alpha decrease collagen synthesis and increase matrix metalloproteinase activity in cardiac fibroblasts in vitro. Circ Res 2000; 86(12):1259-65.

[43] Nah DY, Rhee MY. The inflammatory response and cardiac repair after myocardial infarction. Korean Circ J 2009; 39(10): 393-8.

[44] Martin P, Leibovich SJ. Inflammatory cells during wound repair: the good, the bad and the ugly. Trends Cell Biol 2005;15(11): 599607.

[45] Gawaz M, Langer H, May AE. Platelets in inflammation and atherogenesis. J Clin Invest 2005; 115(12): 3378-84.

[46] Del Conde I, Cruz MA, Zhang H, Lopez JA, Afshar-Kharghan V. Platelet activation leads to activation and propagation of the complement system. J Exp Med 2005; 201(6): 871-9.

[47] Frangogiannis NG, Mendoza LH, Smith CW, Michael LH, Entman $\mathrm{ML}$. Induction of the synthesis of the $\mathrm{C}-\mathrm{X}-\mathrm{C}$ chemokine interferongamma-inducible protein-10 in experimental canine endotoxemia. Cell Tissue Res 2000; 302(3): 365-76.

[48] Zymek P, Nah DY, Bujak M, et al. Interleukin-10 is not a critical regulator of infarct healing and left ventricular remodeling. Cardiovasc Res 2007; 74(2): 313-22.

[49] Finkel MS, Oddis CV, Jacob TD, Watkins SC, Hattler BG, Simmons RL. Negative inotropic effects of cytokines on the heart mediated by nitric oxide. Science 1992; 257(5068): 387-9.

[50] Yokoyama T, Vaca L, Rossen RD, Durante W, Hazarika P, Mann DL. Cellular basis for the negative inotropic effects of tumor necrosis factor-alpha in the adult mammalian heart. J Clin Invest 1993; 92(5): 2303-12.

[51] Engel D, Peshock R, Armstong RC, Sivasubramanian N, Mann DL. Cardiac myocyte apoptosis provokes adverse cardiac remodeling in transgenic mice with targeted TNF overexpression. Am J Physiol Heart Circ Physiol 2004; 287(3): H1303-11.

[52] Fineschi V, Di Paolo M, Neri M, et al. Anabolic steroid- and exercise-induced cardio-depressant cytokines and myocardial $\beta 1$ receptor expression in CD1 mice. Curr Pharm Biotechnol 2011; 12(2): 275-84.

[53] Neri M, Bello S, Bonsignore A, et al. Myocardial expression of TNF-alpha, IL-1beta, IL-6, IL-8, IL-10 and MCP-1 after a single MDMA dose administered in a rat model. Curr Pharm Biotechnol 2010; 11(5): 413-20.

[54] Riezzo I, Pomara C, Neri M, Turillazzi E, Fineschi V. Myocardial tumor necrosis factor-alpha expression in a sudden death due to di- 
lated cardiomyopathy with endomyoelastofibrosis. Int J Cardiol 2009; 134(2): e62-5.

[55] Neri M, Cerretani D, Fiaschi AI, et al. Correlation between cardiac oxidative stress and myocardial pathology due to acute and chronic norepinephrine administration in rats. J Cell Mol Med 2007; 11(1): 156-70.

[56] Irwin MW, Mak S, Mann DL, et al. Tissue expression and immunolocalization of tumor necrosis factor-alpha in postinfarction dysfunctional myocardium. Circulation 1999; 99(11): 1492-8.

[57] Herskowitz A, Choi S, Ansari AA, Wesselingh S. Cytokine mRNA expression in postischemic/reperfused myocardium. Am J Pathol 1995; 146(2): 419-28

[58] Chandrasekar B, Colston JT, Freeman GL. Induction of proinflammatory cytokine and antioxidant enzyme gene expression following brief myocardial ischaemia. Clin Exp Immunol 1997; 108(2): 346-51.

[59] Kurrelmeyer KM, Michael LH, Baumgarten G, et al. Endogenous tumor necrosis factor protects the adult cardiac myocyte against ischemic-induced apoptosis in a murine model of acute myocardial infarction. Proc Natl Acad Sci USA 2000; 97(10): 5456-61.

[60] Dinarello CA. The role of the interleukin-1-receptor antagonist in blocking inflammation mediated by interleukin-1. N Engl J Med 2000; 343(10): 732-4.

[61] Matsushima K, Oppenheim JJ. Interleukin 8 and MCAF: novel inflammatory cytokines inducible by IL 1 and TNF. Cytokine 1989; 1(1): 2-13.

[62] Marui N, Offermann MK, Swerlick R, et al. Vascular cell adhesion molecule-1 (VCAM-1) gene transcription and expression are regulated through an antioxidant-sensitive mechanism in human vascular endothelial cells. J Clin Invest 1993; 92(4): 1866-74.

[63] Bonetti A, Marchini M, Ortolani F. Immunolocalization of interleukin-1 receptor antagonist in healthy and infarcted myocardium. Histol Histopathol 2008; 23(9): 1093-102.

[64] Guillen I, Blanes M, Gomez-Lechon MJ, Castell JV. Cytokine signaling during myocardial infarction: sequential appearance of IL-1 beta and IL-6. Am J Physiol 1995; 269(2 Pt 2): R229-35.

[65] Sica A, Matsushima K, Van Damme J, et al. IL-1 transcriptionally activates the neutrophil chemotactic factor/IL- 8 gene in endothelial cells. Immunology 1990; 69(4): 548-53.

[66] Sica A, Wang JM, Colotta F, et al. Monocyte chemotactic and activating factor gene expression induced in endothelial cells by IL-1 and tumor necrosis factor. J Immunol 1990; 144(8): 3034-8.

[67] Bevilacqua MP, Pober JS, Wheeler ME, Cotran RS, Gimbrone MA Jr. Interleukin 1 acts on cultured human vascular endothelium to increase the adhesion of polymorphonuclear leukocytes, monocytes, and related leukocyte cell lines. J Clin Invest 1985; 76(5): 2003-11.

[68] Hakkert BC, Kuijpers TW, Leeuwenberg JF, van Mourik JA, Roos D. Neutrophil and monocyte adherence to and migration across monolayers of cytokine-activated endothelial cells: the contribution of CD18, ELAM-1, and VLA-4. Blood 1991; 78(10): 2721-6.

[69] Colotta F, Re F, Polentarutti N, Sozzani S, Mantovani A. Modulation of granulocyte survival and programmed cell death by cytokines and bacterial products. Blood 1992; 80(8): 2012-20.

[70] Ing DJ, Zang J, Dzau VJ, Webster KA, Bishopric NH. Modulation of cytokine-induced cardiac myocyte apoptosis by nitric oxide, Bak, and Bcl-x. Circ Res 1999; 84(1): 21-33.

[71] Gurantz D, Cowling RT, Varki N, Frikovsky E, Moore CD, Greenberg BH. IL-1beta and TNF-alpha upregulate angiotensin II type 1 (AT1) receptors on cardiac fibroblasts and are associated with increased AT1 density in the post-MI heart. J Mol Cell Cardiol 2005; 38(3): 505-15.

[72] Mitchell MD, Laird RE, Brown RD, Long CS. IL-1beta stimulates rat cardiac fibroblast migration via MAP kinase pathways. Am J Physiol Heart Circ Physiol 2007; 292(2): H1139-47.

[73] Bujak M, Dobaczewski M, Chatila K, et al. Interleukin-1 receptor type I signaling critically regulates infarct healing and cardiac remodeling. Am J Pathol 2008; 173(1): 57-67.

[74] Aoyama T, Takimoto Y, Pennica D, et al. Augmented expression of cardiotrophin-1 and its receptor component, gp130, in both left and right ventricles after myocardial infarction in the rat. $\mathrm{J} \mathrm{Mol}$ Cell Cardiol 2000; 32(10): 1821-30.

[75] Kukielka GL, Smith CW, Manning AM, Youker KA, Michael LH, Entman ML. Induction of interleukin-6 synthesis in the myocardium. Potential role in postreperfusion inflammatory injury. Circulation 1995; 92(7): 1866-75.
[76] Silvestre JS, Mallat Z, Duriez M, et al. Antiangiogenic effect of interleukin-10 in ischemia-induced angiogenesis in mice hindlimb. Circ Res 2000; 87(6): 448-52.

[77] Lu L, Gunja-Smith Z, Woessner JF, et al. Matrix metalloproteinases and collagen ultrastructure in moderate myocardial ischemia and reperfusion in vivo. Am J Physiol Heart Circ Physiol 2000; 279(2): H601-9.

[78] Rohde LE, Ducharme A, Arroyo LH, et al. Matrix metalloproteinase inhibition attenuates early left ventricular enlargement after experimental myocardial infarction in mice. Circulation 1999; 99(23): 3063-70.

[79] Gwechenberger M, Mendoza LH, Youker KA, et al. Cardiac myocytes produce interleukin- 6 in culture and in viable border zone of reperfused infarctions. Circulation 1999; 99(4):546-51.

[80] Frangogiannis NG, Lindsey ML, Michael LH, et al. Resident cardiac mast cells degranulate and release preformed TNF-alpha, initiating the cytokine cascade in experimental canine myocardial ischemia/reperfusion. Circulation 1998; 98(7): 699-10.

[81] Birdsall HH, Green DM, Trial J, et al. Complement C5a, TGF-beta 1 , and $\mathrm{MCP}-1$, in sequence, induce migration of monocytes into ischemic canine myocardium within the first one to five hours after reperfusion. Circulation 1997; 95(3): 684-92.

[82] Kumar AG, Ballantyne CM, Michael LH, et al. Induction of monocyte chemoattractant protein-1 in the small veins of the ischemic and reperfused canine myocardium. Circulation 1997; 95(3): 693700 .

[83] Salcedo R, Ponce ML, Young HA, et al. Human endothelial cells express CCR2 and respond to MCP-1: direct role of MCP-1 in angiogenesis and tumor progression. Blood 2000; 96(1): 34-40.

[84] Gharaee-Kermani M, Denholm EM, Phan SH. Costimulation of fibroblast collagen and transforming growth factor betal gene expression by monocyte chemoattractant protein-1 via specific receptors. J Biol Chem 1996; 271(30): 17779-84.

[85] Gavrilin MA, Deucher MF, Boeckman F, Kolattukudy PE. Monocyte chemotactic protein 1 upregulates IL-1beta expression in human monocytes. Biochem Biophys Res Commun 2000; 277(1): 3742.

[86] Jiang Y, Beller DI, Frendl G, Graves DT. Monocyte chemoattractant protein-1 regulates adhesion molecule expression and cytokine production in human monocytes. J Immunol 1992; 148(8): 2423-8.

[87] Tabata T, Mine S, Kawahara C, Okada Y, Tanaka Y. Monocyte chemoattractant protein-1 induces scavenger receptor expression and monocyte differentiation into foam cells. Biochem Biophys Res Commun 2003; 305(2): 380-5.

[88] Youker KA, Hawkins HK, Kukielka GL, et al. Molecular evidence for induction of intracellular adhesion molecule-1 in the viable border zone associated with ischemia-reperfusion injury of the dog heart. Circulation 1994; 89(6): 2736-46.

[89] Albelda SM, Smith CW, Ward PA. Adhesion molecules and inflammatory injury. FASEB J 1994; 8(8): 504-12.

[90] Smith CW, Marlin SD, Rothlein R, Toman C, Anderson DC. Cooperative interactions of LFA-1 and Mac-1 with intercellular adhesion molecule-1 in facilitating adherence and transendothelial migration of human neutrophils in vitro. J Clin Invest 1989; 83(6): 2008-17.

[91] Smith CW. Introduction: functional polarity of motile neutrophils. Blood 2000; 95(8): 2459-61.

[92] Kocher AA, Schuster MD, Bonaros N, et al. Myocardial homing and neovascularization by human bone marrow angioblasts is regulated by IL-8/Gro CXC chemokines. J Mol Cell Cardiol 2006; 40(4): 455-64.

[93] Frangogiannis NG, Mendoza LH, Lindsey ML, et al. IL-10 is induced in the reperfused myocardium and may modulate the reaction to injury. J Immunol 2000; 165(5): 2798-808.

[94] Yang Z, Zingarelli B, Szabó C. Crucial role of endogenous interleukin-10 production in myocardial ischemia/reperfusion injury. Circulation 2000; 101(9): 1019-26.

[95] Jaeschke H, Smith CW. Mechanisms of neutrophil-induced parenchymal cell injury. J Leukoc Biol 1997; 61(6): 647-53.

[96] Frangogiannis NG, Burns AR, Michael LH, Entman ML. Histochemical and morphological characteristics of canine cardiac mast cells. Histochem J 1999; 31(4): 221-9.

[97] Frangogiannis NG, Perrard JL, Mendoza LH, et al. Stem cell factor induction is associated with mast cell accumulation after canine myocardial ischemia and reperfusion. Circulation 1998; 98(7): 68798. 
[98] He S, Peng Q, Walls AF. Potent induction of a neutrophil and eosinophilrich infiltrate in vivo by human mast cell tryptase: selective enhancement of eosinophil recruitment by histamine. J Immunol 1997; 159(12): 6216-25

[99] Compton SJ, Cairns JA, Holgate ST, Walls AF. The role of mast cell tryptase in regulating endothelial cell proliferation, cytokine release, and adhesion molecule expression: tryptase induces expression of mRNA for IL-1 beta and IL- 8 and stimulates the selective release of IL-8 from human umbilical vein endothelial cells. J Immunol 1998; 161(4): 1939-46.

[100] Somasundaram P, Ren G, Nagar H, et al. Mast cell tryptase may modulate endothelial cell phenotype in healing myocardial infarcts. J Pathol 2005; 205(1): 102-11.

[101] Ruoss SJ, Hartmann T, Caughey GH. Mast cell tryptase is amitogen for cultured fibroblasts. J Clin Invest 1991; 88 (2): 493-9.

[102] Gruber BL, Kew RR, Jelaska A, et al. Human mast cells activate fibroblasts: tryptase is a fibrogenic factor stimulating collagen messenger ribonucleic acid synthesis and fibroblast chemotaxis. J Immunol 1997; 158(5): 2310-7.

[103] Hatamochi A, Fujiwara K, Ueki H. Effects of histamine on collagen synthesis by cultured fibroblasts derived from guinea pig skin. Arch Dermatol Res 1985; 277(1): 60-4.

[104] Qu Z, Liebler JM, Powers MR, et al. Mast cells are a major source of basic fibroblast growth factor in chronic inflammation and cutaneous hemangioma. Am J Pathol 1995; 147(3): 564-73.

[105] Boesiger J, Tsai M, Maurer M, et al. Mast cells can secrete vascular permeability factor/ vascular endothelial cell growth factor and exhibit enhanced release after immunoglobulin E-dependent upregulation of fc epsilon receptor I expression. J ExpMed 1998; 188(6): 1135-45.

[106] Shiota N, Rysa J, Kovanen PT, Ruskoaho H, Kokkonen JO, Lindstedt KA. A role for cardiac mast cells in the pathogenesis of hypertensive heart disease. J Hypertens 2003; 21(10): 1935-44.

[107] Kukielka GL, Youker KA, Hawkins HK, et al. Regulation of ICAM-1 and IL-6 in myocardial ischemia: effect of reperfusion. Ann N Y Acad Sci 1994; 723: 258-70.

[108] Oyamada S, Bianchi C, Takai S, Chu LM, Sellke FW. Chymase inhibition reduces infarction and matrix metalloproteinase- 9 activation and attenuates inflammation and fibrosis after acute myocardial ischemia/reperfusion. J Pharmacol Exp Ther 2011; 339(1): 143-51.

[109] Li JK, Du WJ, Jiang SL, Tian H. Expression of ADAM-15 in rat myocardial infarction. Int J Exp Pathol 2009; 90(3): 347-54.

[110] Kratzschmar J, Lum L, Blobel CP. Metargidin, a membrane anchored metalloprotease-disintegrin protein with an RGD integrin binding sequence. J Biol Chem 1996; 271(9): 4593-6.

[111] Hu Y, Zhang H, Lu Y, et al. Class A scavenger receptor attenuates myocardial infarction-induced cardiomyocyte necrosis through suppressing M1 macrophage subset polarization. Basic Res Cardiol 2011; 106(6): 1311-28.

[112] Dawn B, Xuan YT, Guo Y, et al. IL-6 plays an obligatory role in late preconditioning via JAK-STAT signaling and upregulation of iNOS and COX-2. Cardiovasc Res 2004; 64(1): 61-71.
[113] Bkaily G, Pothier P, D’Orléans-Juste P, et al. The use of confocal microscopy in the investigation of cell structure and function in the heart, vascular endothelium and smooth muscle cells. Mol Cell Biochem 1997; 172(1-2):171-94.

[114] Borg TK, Stewart JA Jr, Sutton MA. Imaging the cardiovascular system: seeing is believing. Microsc Microanal 2005; 11(3): 18999

[115] Wedekind H, Schulze-Bahr E, Debus V, Breithardt G, Brinkmann B, Bajanowski T. Cardiac arrhythmias and sudden death in infancy: implication for the medicolegal investigation. Int $\mathrm{J}$ Legal Med 2007; 121(4): 245-57.

[116] Gómez AM, Schwaller B, Porzig H, Vassort G, Niggli E, Egger M. Increased exchange current but normal $\mathrm{Ca} 2+$ transport via $\mathrm{Na}+$ $\mathrm{Ca} 2+$ exchange during cardiac hypertrophy after myocardial infarction. Circ Res 2002; 91(4): 323-30.

[117] Li XQ, Zhao MG, Mei QB, et al. Effects of tumor necrosis factoralpha on calcium movement in rat ventricular myocytes. Acta Pharmacol Sin 2003; 24(12):1224-30.

[118] Hein S, Kostin S, Schaper J. Adult rat cardiac myocytes in culture: 'Second-floor' cells and coculture experiments. Exp Clin Cardiol 2006; 11(3): 175-82.

[119] Wang HJ, Jiang HL, Chen XH, Lin PY, Zhu YC, Tao LL. The antiapoptosis effect of erythropoietin on neonatal rat cardiocytes during hypoxia/reoxygenation injury and its possible mechanism. Zhongguo Wei Zhong Bing Ji Jiu Yi Xue 2010; 22(5): 302-5.

[120] Matsushita T, Takamatsu T. Ischaemia-induced temporal expression of connexin43 in rat heart. Virchows Arch 1997; 431(6): 4538.

[121] Bowers SL, Borg TK, Baudino TA. The dynamics of fibroblastmyocyte-capillary interactions in the heart. Ann N Y Acad Sci 2010; 1188: 143-52

[122] Ogawa M, Harada Y, Yamaoka Y, Fujita K, Yaku H, Takamatsu T. Label-free biochemical imaging of heart tissue with high-speed spontaneous Raman microscopy. Biochem Biophys Res Commun 2009; 382(2): 370-4

[123] Buschman HP, Deinum G, Motz JT, et al. Raman microspectroscopy of human coronary atherosclerosis: biochemical assessment of cellular and extracellular morphologic structures in situ. Cardiovasc Pathol 2001; 10(2): 69-82.

[124] Buschman HP, Motz JT, Deinum G, et al. Diagnosis of human coronary atherosclerosis by morphology-based Raman spectroscopy. Cardiovasc Pathol 2001; 10(2):59-68.

[125] Ko AC, Ridsdale A, Smith MS, et al. Multimodal nonlinear optical imaging of atherosclerotic plaque development in myocardial infarction-prone rabbits. J Biomed Opt 2010; 15(2): 020501.

[126] Kempf T, Zarbock A, Vestweber D, Wollert KC. Antiinflammatory mechanisms and therapeutic opportunities in myocardial infarct healing. J Mol Med (Berl) 2012; 90(4): 361-9.

[127] Frangogiannis NG. Regulation of the inflammatory response in cardiac repair. Circ Res 2012;110(1): 159-73.

Received: September 10, 2012 Revised: October 20, 2012 Accepted: November 6, 2012 